\title{
Proposed solutions of accidents resulting use of 3D coordinate technology in the civil engineering industry
}

\author{
Amr Salah H. R. Ali ${ }^{1,4}$, Lilik Ariyanto ${ }^{2}$, and Salah H. R. Ali ${ }^{3,4^{*}}$ \\ ${ }^{1}$ Business Info Systems Program, Helwan University, Cairo, Egypt \\ ${ }^{2}$ Civil Engineering Department, Faculty of Engineering, Sang Bumi Ruwa Jurai University \\ ${ }^{3}$ Precision Engineering Division, National Institute for Standards (NIS), Giza, Egypt \\ ${ }^{4}$ Ministry of Higher Education and Scientific Research, Egypt
}

\begin{abstract}
Mechanical engineers have adapted 3D coordinate technology in the design and implementation of cranes to accelerate the production of construction industries, especially tall structures such as buildings and bridges. Structural engineering projects such as buildings, infrastructure, and bridges are central to the development of human civilization. However, it is also a source of some types of accidents and even disasters, which will be referred to in this paper as structural engineering disasters. This paper discusses the concept, types, and characteristics of structural engineering disasters, especially those that talk about the use of high-level 3D coordinate equipment (tower or mobile cranes) and ways to mitigate them. The accidents in practice occur due to dynamic balance defects during equipment operation, which is usually due to incorrect selection or behavior on the construction site, installation, maintenance, operation, or ambient environmental conditions. Structural engineering disasters occur frequently and globally because they are closely related to human behavior and performance. This paper confirms that solutions can be found entrepreneurial to manage the situation to reach the appropriate operation to mitigate the accidents, through implementing the proposed administrative and engineering recommendations related to an accurate scientific method to meet these challenges. The engineering recommendations are based on ensuring the proper implementation of maintenance, operation, and calibration under the engineering standards. While the administrative recommendations focus on ensuring the follow-up of the safety procedures for implementing maintenance programs and the appropriate behavior of operator and scientifically signal person to meet these challenges.
\end{abstract}

\section{Introduction}

Advances in cosmic civilization made 3D coordinate technology play an important role in engineering industries, especially the civil and construction industry. The civil and construction industry is one of the axes of the development plan of the world's countries. There are many engineering machines and equipment are designed by mechanical designer engineers to serve the construction industry based on the idea of 3D coordinate technology. This equipment has played a huge role in the progress of the construction industry, especially cranes. The operation of the crane is generally based on wire ropes or chains and beams. The efficient and safe operation of the cranes is of paramount importance to the safety of workers and the execution of works according to the schedule of the project program. Of course, the safe operation of the cranes brings the overall success of the project [1]. Cranes are the lifeline of the construction industry, while their accidents are still too frequent.
Cranes are the lifeline of the construction industry, while their accidents are still very frequent. This is because they're operating at high altitudes, which contributes to the highest mortality rate in the construction industry as a result of bad human behaviors. Therefore, human behavior is an influential factor, whether in technical or administrative work. However, without proper safety management of cranes on construction sites, accidents that could be catastrophic for some people can occur due to loss of life and property.

There are many studies concerned with the design, manufacture, and testing of cranes [2, 7]. Many studies have been concerned with human behavior [4, 8], as operator and signalman and technician. However, there is a lack of systematic research on the relationship between the personality and unsafe behavior of construction workers. In general, the causes of construction risks can be categorized into three main factors: the customer, the contractor (the builder), and the designer [9]. Estimates suggest that the crane's operation is involved in up to onethird of fatalities in all construction and maintenance [10,

\footnotetext{
${ }^{*}$ Corresponding author: SalahAli20@yahoo.com
} 
13]. Not to mention the number of injuries or damage to the cranes, equipment, and buildings around them. In light of this danger, there is always an urgent necessity to study the sources of accidents to find suitable solutions for them. Although some cranes are equipped with advanced safety technologies, accidents such as blind lifting and poor contact can lead to machine failure and death [7].

On the other hand, few studies have concerned the development of crane layout planning (CLP) in construction projects of modular integrated construction (MiC). In construction operations, the movement of the crane is repeated to suspend the load and transport it to the specified location. Undoubtedly, this requires careful planning such as selecting a suitable crane and choosing the position of the crane in terms of productivity and safety so that the performance is carried out accurately and thus the transfer process is successful. These studies can be categorized into mobile crane optimization $[14,16]$, investigation of potential working areas of mobile cranes $[17,18]$, and mobile crane lifting trajectory optimization $[19,22]$. It becomes clear that the studies related to CLP development of $\mathrm{MiC}$ in construction projects are still very few $[23,24]$.

The objectives of this article aim to search for sources of errors that lead to crane accidents during operation in construction projects. In addition to providing entrepreneurial solutions proposals on two grounds: the risks resulting from human errors, whether administrative, from lack of follow-up and technical errors in light of international Standards of CLP for MiC.

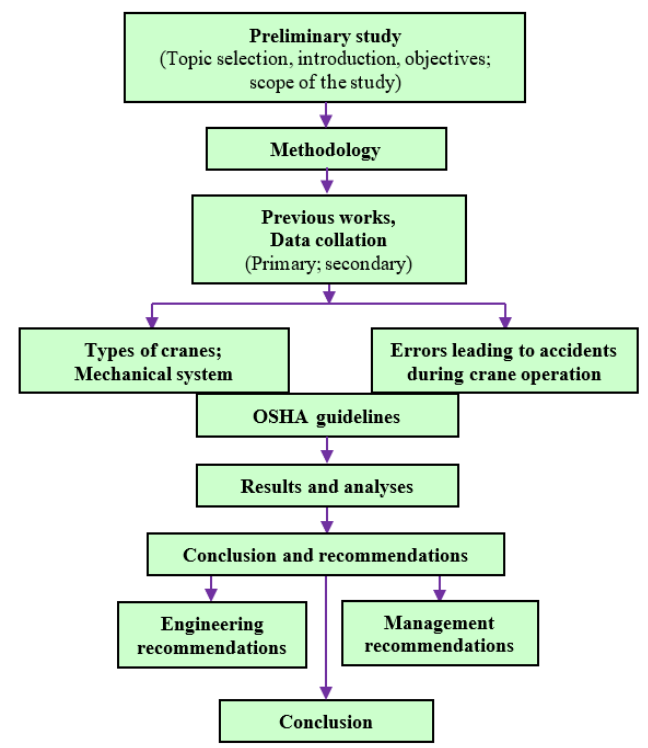

Fig. 1. Schematic flow diagram of the proposed methodology

The methodology used in this paper is presented in detail as mentioned in Fig.1. The objectives were set, the results of questionnaires, case studies, and the result of a personal interview with expert committees were read to compile information related to crane safety in the construction industry. Some secondary data was also collected from several research articles, books, online cranes companies, and previous research.

\section{Entrepreneurial Management for Mechanical System}

The relationship between entrepreneurial management and industrial enterprises will present in this section. This includes presenting a brief overview of the concept and history of entrepreneurship and the ambitions we aspire to in this work. Moreover, we will provide a summary of the common commercial types of cranes used in construction engineering projects, in addition to some design factors that must be taken into account for the cranes to operate in a safe dynamic manner.

\subsection{Entrepreneurship in the Mechanical System for Sustainable Development}

Entrepreneurship plays an important role in the safety management of sustainable engineering equipment and machinery in the industry, particularly when operating cranes. Entrepreneurial thinking is the way to operate and maintain cranes and equipment. This ensures successful construction projects and outstanding profits. The term "entrepreneurship" appeared with the need to make institutional projects for commercial industrial activities during the 1960s in European countries. Entrepreneurship in its early days was influenced by a range of humanities such as economics, marketing, sociology, behavioral psychology, management, and history.

Currently, without a doubt, information and communication technology (I\&CTs) has contributed to maximizing the role of pioneering businesses for the success of many projects [25]. Studies have confirmed that the modern concept of entrepreneurship depends on a management's willingness to work rationally to organize the work of projects in light of the opportunities and challenges to achieve their ambitions, then serve the community and achieve profits [26, 28]. This makes entrepreneurship the main requirement as a step for the success of projects following its objectives to participate in the development of the economy. Hence, the importance of studying the behavior of employees' performance has become an important requirement that must be focused on for the success of projects. This leads to the continued implementation of engineering construction projects. Hence, in this paper, we were keen to present pioneering recommendations suggested as solutions to reduce the problems of crane damage and accidents. In addition, we would like to inform the community and engineers of the importance and power of entrepreneurship in the success of projects.

\subsection{Types of Cranes and Mechanical System}

Dynamic balance is considered one of the main causes of breakdown for carinas during the operation of equipment used in construction engineering projects. So, this section includes a review most common types of cranes used in the construction and civil industry, as well as presents a description detailed from the view of the mechanical design of one of the commonly used crane structures. 


\subsubsection{Types of construction cranes}

Practically, all construction projects have goals and strategies for implementing the goals and end with a feasibility study to achieve profits. Many types of cranes are used in construction and industrial projects [29, 31]. There are also many factors that a project manager should consider in choosing the right type of crane to be recommended, including but not limited to the following: Safety and properly use, Weather, Project terrain, Power and torque, Loads, Heights, The area and size of the project, Project time and duration, productivity, and cost, etc. Therefore, one or more of these types of levers can be selected to achieve the objectives and feasibility of the project. More information about common types of cranes used in construction projects can be found in the following reference [29].

Table 1: Common types of commercial cranes

\begin{tabular}{|c|l|l|}
\hline No. & $\begin{array}{l}\text { Name of } \\
\text { Crane }\end{array}$ & \multicolumn{1}{|c|}{ Description (Key feature, Uses) } \\
\hline $1-$ & Carry Deck & $\begin{array}{l}\text { Versatility and movability, Loading } \\
\text { and moving materials on job sites. }\end{array}$ \\
\hline $2-$ & Crawler & $\begin{array}{l}\text { Tracks instead of wheels, Jobs with } \\
\text { soft/uneven terrain. }\end{array}$ \\
\hline $3-$ & Floating & $\begin{array}{l}\text { Ability to work in water, Projects on } \\
\text { the sea like ports or oil rigs. }\end{array}$ \\
\hline $4-$ & $\begin{array}{l}\text { Rough } \\
\text { Terrain }\end{array}$ & $\begin{array}{l}\text { Four rubber tires (four-wheel drive), } \\
\text { Pick and carry operations on rough } \\
\text { terrain. }\end{array}$ \\
\hline $5-$ & $\begin{array}{l}\text { Truck- } \\
\text { mounted }\end{array}$ & $\begin{array}{l}\text { Ability to travel on the highway, For } \\
\text { loading and moving equipment on job } \\
\text { site. }\end{array}$ \\
\hline $6-$ & $\begin{array}{l}\text { Bridge/Overh } \\
\text { ead }\end{array}$ & $\begin{array}{l}\text { Reliable stability and efficiency, } \\
\text { Typically used for industrial } \\
\text { environments. }\end{array}$ \\
\hline $7-$ & $\begin{array}{l}\text { Bulk- } \\
\text { handling }\end{array}$ & $\begin{array}{l}\text { The large grabbing-like mechanism, } \\
\text { Lifting \& moving bulk cargo like coal } \\
\text { or scrap metal. }\end{array}$ \\
\hline 8- & Hammerhead & $\begin{array}{l}\text { Racking-ability for the trolley to } \\
\text { move back and forth, One of the most } \\
\text { commonly used crane types. }\end{array}$ \\
\hline 9- & Stacker & $\begin{array}{l}\text { The forklift-like mechanism, } \\
\text { Retrieval of cargo in warehouse } \\
\text { storage. }\end{array}$ \\
\hline $11-$ & Tower & $\begin{array}{l}\text { Hydraulic cylinder for changing } \\
\text { length, Highly adaptable for a variety } \\
\text { of mobile situations. }\end{array}$ \\
$\begin{array}{l}\text { Height and weight-lifting capabilities, } \\
\text { Building large structures. }\end{array}$ \\
\hline
\end{tabular}

Once all the data and technical specifications for the project are available, then the technical manager can decide what type of crane need for successful construction work as shown in Table 1.

Experimentally, a tower crane is an essential commonly used tool in the construction projects such as bridges and tall buildings, due to the ability to lift heavy materials and various features. This is due to its amazing lifting capabilities. Due to the big size of the tower crane, it is equipped with a high operating cab that controls all motions. The Tower crane is also having 6 different types as follows: Luffing tower crane, an A-frame tower crane, a Flat top tower crane, a Self-erecting tower crane, a Portal tower crane, and a Remote control crane [31]. Whereas the idea and the working theory of all tower cranes are the same, but the deferent is manly in the height and power, weight. Thus, we will review the design, structure, and dynamic safety of the tower crane in the next section.

\subsubsection{Mechanical design and dynamic safety of cranes}

In the late 1940s, Hans Liebherr group (German design engineers) invented the first mobile tower crane. While as a result of advances in various life sciences, cranes are made up of the parts shown in Fig. 2 [32]. The specific definition of a tower crane is a mechanical system designed and equipped with electrical motors to lift and transport loads or materials through a hook suspended from a movable boom. More information about the technical development throughout the history of the cranes can be found in the following reference [33]. Fig. 3 shows the importance of considering the role of geometric dimensions in achieving dynamic balance during operation as a necessity for safety $[32,34]$.

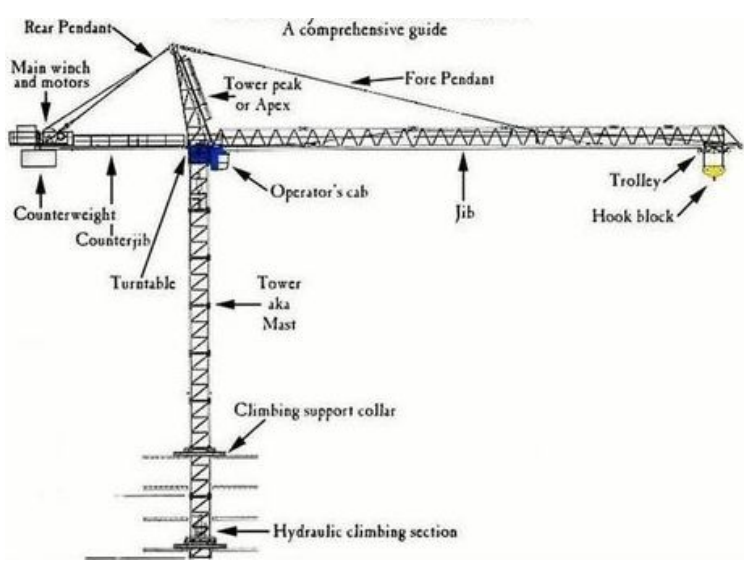

Fig. 2. Skeleton of a tower crane

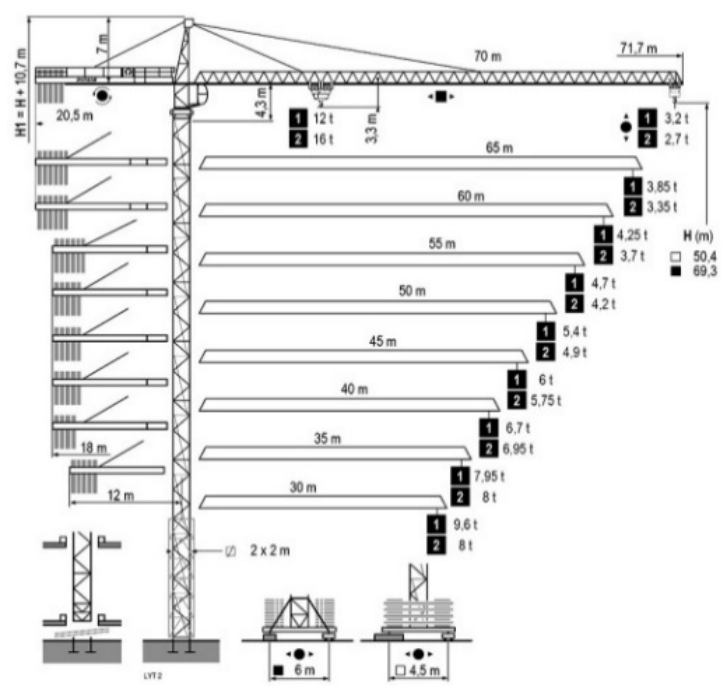

Fig. 3. Effects of dimensions of dynamic safety [34] 
Many scientific kinds of research have been concerned with studying the design, construction, and dynamic control of cranes operation in construction projects [35][38]. Most of the research has focused on the study of the dynamic to insuring and achieving safe operation [37][39]. Fig. 4 shows some results of a study that demonstrated that the trajectory of the load carried $\mathrm{H}$ the working conditions are the least favorable as there is a risk of a loss of the crane system stability using three different variants [38]. Where $t$ is the operation time.

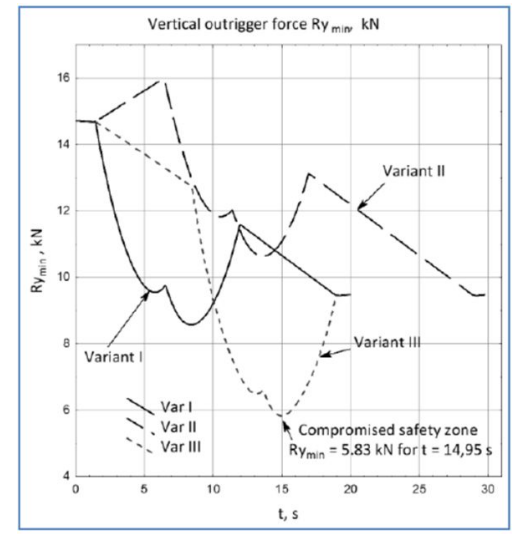

a)

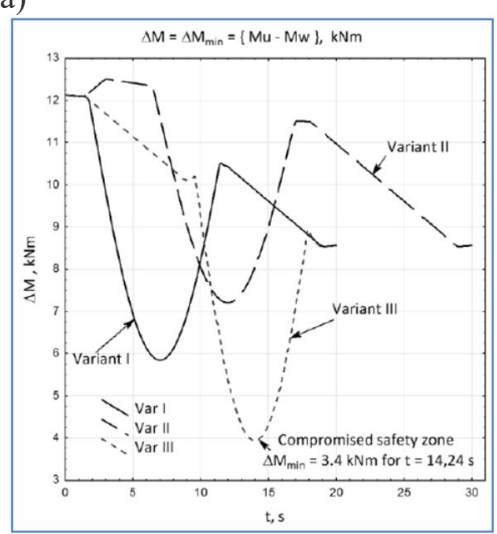

b)

Fig.4. Stability indicator for safety due to operation conditions during displacement of the cargo for the 3 different variants of handling assignment at values of a) and b)

The overturning torque $M w$ is counteracted by the stabilizing torque $M u$ with an opposite direction that is dependent on the mass and the location of the mass center of the crane elements, in the absolute coordinate system Oxyz. There are indicators necessary to ensure the safety of cranes in operation during operation in the construction industry. On the other hand, the tower and mobile cranes should include the safety devices or indicators according to EN 17076:2020 standards [40, 42] such as Obstacle lights, Height limiter, Slewing limiter, Range/trolley limiter, Weight limiter, Moment imiter and Anemometer and block box (optional). Fig. 5 shows several practical device indicators are equipped in a tower crane to ensure good vision, monitoring, and follow-up performance to ensure safety during operating $[42,43]$.

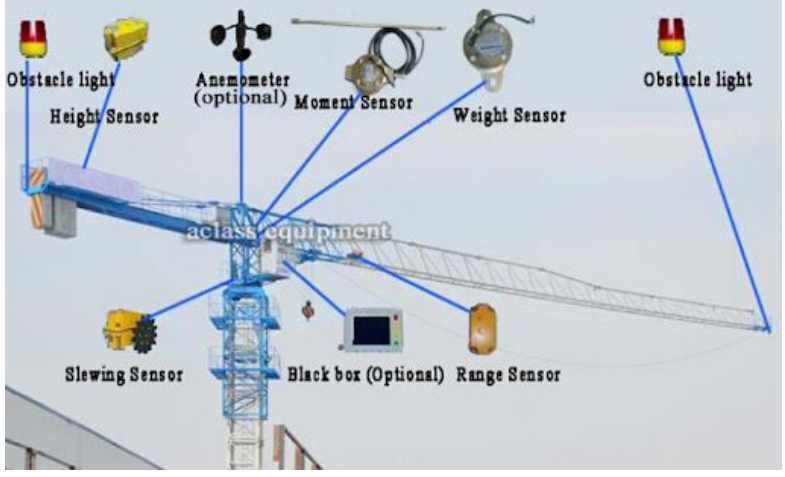

Fig. 5. Safety devices used in tower cranes according to Standards [42]

\section{Errors Leading to Accidents during Tower Crane Operation (Structural Engineering Disasters)}

Structural engineering disasters due to crane accidents lead to a variety of causes. Many errors lead to accidents during the operation of the cranes such as technical errors, and administrative or behavioral errors. When cranes fail, the results are often disastrous due to the height, size, and weight of crane structures (cab, boom, and tower) and their loads. This is mainly due to the dynamic instability during operation due to technical and management errors. Where studies have shown that the imbalance is caused by various errors such as crane bending of excessive loads, crane failure due to wind and weather conditions, incorrect assembly, unused proper safety procedures, improper operator training, operator error, poor maintenance, mechanical fatigue and wear, connect with electrical power lines, or failure to perform regular or appropriate safety checks [44, 47].

This section will focus on errors percentage caused by technical and administrative errors. Fig. 6 illustrates two of the crane collapse accidents in the projects sites that occurred in New York around 2015 and New Jersey and claimed the lives of several people and damaged property, which could amount to disasters.

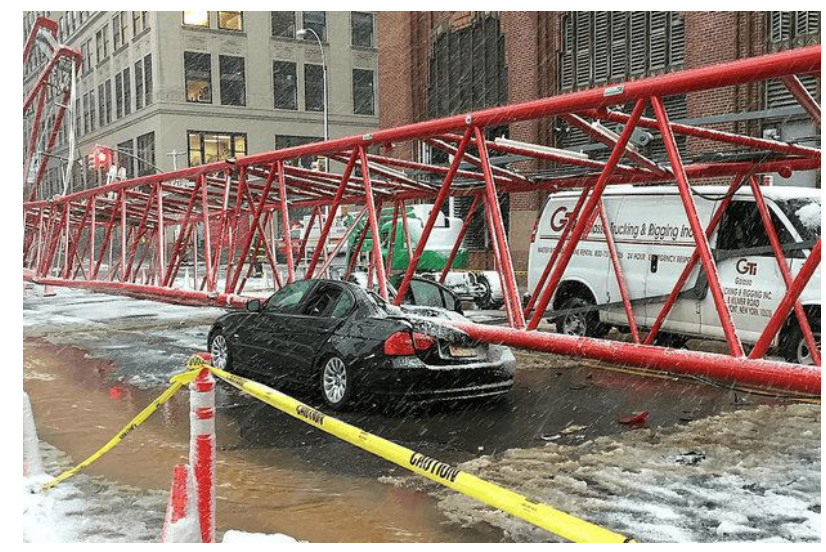

a)At New York, the US, 205 [45] 


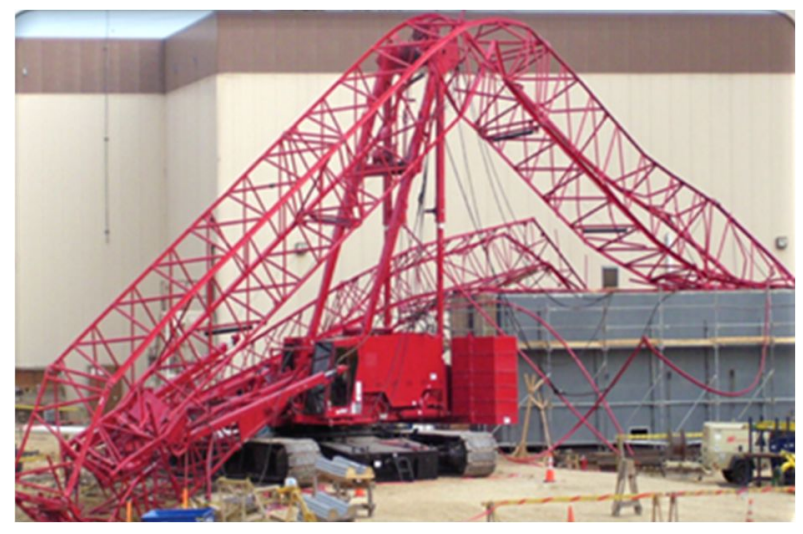

b) At New Jersey (BECHT Co), US [47]

Fig. 6. Pictures from real accidents that happened for some tower cranes in America

The facts have confirmed that crane accidents are relatively more serious than other construction equipment accidents, and also the most costly of all in terms of insurance claims and lawsuits. The study has shown that accidents caused by the use of mobile cranes in the construction industry are due to many technical and behavioral reasons, environmental conditions, and location. While a recent study [46] confirmed that the mortality rate when operating mobile cranes is due to the following reasons: loads $14 \%$, drilling equipment $15 \%$, electrocution $44 \%$, operator error overloading $7 \%$, and $7 \%$ due to boom breakage, $5 \%$ failure Wire rope, miscellaneous $3 \%$, the result of hitting the worker with the winch is $5 \%$. The study also attributed the main causes of mobile crane accidents to high winds $1.6 \%$, machinery and structure failure $11.2 \%$, outrigger failure $22.6 \%$, support failure $31.5 \%$, and operator error $33.1 \%$. Technical and administrative errors along with behavioral errors are the most important sources of mobile crane accidents.

\section{Results and Analyses}

Of course for each type of crane, they have a different type of failure depending on the design and operation. For example, the tower and mobile crane fail due to vibrationinduced poor dynamic balance in operation, and the tower crane fails due to the straightened failure of the crane's steel support structure [9]. While, the examination and study of questionnaires related to the topic of the research, the results were presented in this section. Table 2 shows some of some important recommendations results to reduce tower crane failure and accidents as a function of error sources in the construction industry [9].

Analyzes have shown that crane failure considers Ahmed the most dangerous factor of all, as it can lead to permanent disabilities or even death. Therefore, the Occupational Safety and Health Administration (OSHA) has guidelines several workplace safety standards within CLP of MiC to reduce these risks or accidents, so site workers should follow these instructions to increase the level of safety.
Table 2: Some recommendation factors to reduce tower crane failure and accidents

\begin{tabular}{|l|c|}
\hline \multicolumn{1}{|c|}{ Recommendation Factors } & $\begin{array}{c}\text { Error } \\
\text { Source }\end{array}$ \\
\hline $\begin{array}{l}\text { Tower crane operator must be eligible and } \\
\text { have a license (competent) }\end{array}$ & Human \\
\hline $\begin{array}{l}\text { Every } 4 \text { hrs. the crane operator needs to } \\
\text { be changed }\end{array}$ & Human \\
\hline $\begin{array}{l}\text { The loading of certain materials or stuff } \\
\text { must be checked with the limitation of the } \\
\text { crane }\end{array}$ & Human \\
\hline $\begin{array}{l}\text { should add a camera which can +zoom in } \\
\text { so that the operator can see signalmen }\end{array}$ & Mechanical \\
\hline $\begin{array}{l}\text { All cranes must be inspected by the } \\
\text { supervisor and safety officer before use }\end{array}$ & Human \\
\hline $\begin{array}{l}\text { Take serious whatever you are doing } \\
\text { because it's involving life }\end{array}$ & Human \\
\hline $\begin{array}{l}\text { Competency in all aspects not just crane } \\
\text { operator, but the rigger and lifting } \\
\text { supervisor + compulsory in lifting plan }\end{array}$ & Human \\
\hline $\begin{array}{l}\text { Weekly must do an inspection and fully } \\
\text { supervise for mobile crane }\end{array}$ & Human \\
\hline Take into accounts the speed of the wind & Human \\
\hline Pay extra attention when working & Human \\
\hline $\begin{array}{l}\text { Competency personnel including lifting } \\
\text { supervisor \& lifting plan for each lifting } \\
\text { operation. }\end{array}$ & Human \\
\hline
\end{tabular}

\section{Conclusion}

The study confirmed that safety management in construction projects has tasks and solutions, in addition to developing the necessary plans and strategies. These tasks should ensure that administrative and technical procedures are always followed up by international standards of CLP to find solutions to maintain a dynamic balance of cranes to mitigate the accidents, as follows:

A) Regarding administrative and management solutions:

1) Follow-up records of test and choose the location and the fixation installation method of crane, taking into account the distribution of crane assignments during work

2) It is forbidden to speak with the crane operator or the signal operator during work.

3) Follow-up records of maintenance and repair and spare parts that have been replaced, as well as records of checking the safety of operation or what is sometimes called calibration.

4) Wind speed and temperature must be measured and carefully taken into account.

5) The importance of following up on the crane operator change dates.

B) Regarding engineering and technical solutions:

1) Prevent the crane from being overloaded for any reason, as it affects its dynamic balance.

2) Avoiding human error because it is the main factor as a result of unplanned movements, which leads to the collapse of the crane, so the crane must be managed entrepreneurial by a specialized person who has been trained, qualified, and experienced in this. 
3) Taking into account the poor communication between the crane operator and the signal operator. The most common mechanical failures are commonly lead to the failure of the crane, especially the mobile crane, which results in the crane falling or overturning.

4) Failure to maintain the crane by an untrained and unspecialized person. Because mechanical failure is the most common cause of crane failure, especially boom failure.

5) Ensure that the crane is calibrated according to the agreed technical standards

6) The crane must be properly and periodically maintained by the competent mechanic under the supervision of the competent engineer under the principles of the crane industry.

7) The effect of wind speed, temperature; precipitation intensity, and rain direction on operation should be taken into account.

Following the precautionary principle and in light of the above, we affirm that all personnel involved in lifting activities must be adequately trained and prepared for the working environment, with the cranes properly maintained under the catalog of the manufacturer's and the industrial assets.

\section{References}

1. Hwang, Seokyon, Automation in Construction, Ultra-wide Band Technology Experiments for Realtime Prevention of Tower Crane Collisions, Automation in Construction, 22, 545-553 (2012).

2. Md. S. Hasan, Interactive and Dynamic Integrated Module for Mobile Cranes Supporting System Design, MSc thesis, University of Alberta, 2008.

3. P. Swuste, A 'normal accident' with a tower crane? An accident analysis was conducted by the Dutch Safety Board, Safety Science, 57, 276-282, (2013).

4. K. Dhalmahapatra, O. Pradhan, S. Das, K. Singh, and J. Maiti, Prioritization of human errors in EOT crane operations and its visualization using virtual simulation,4th Int. Conf. on Recent Advances in Information Technology (RAIT-2018) (2018).

5. M.F. Milazzo \& G. Ancione, V. Spasojevic Brkic, D. Vališ, Investigation of crane operation safety by analyzing main accident causes, Risk, Reliability, and Safety: Innovating Theory and Practice - Walls, Revie \& Bedford (Eds), Taylor \& Francis Group, London, ISBN 978-1-138-02997-2 (2017).

6. Y. Fang a and Y. K. Chob, Measuring Operator's Situation Awareness in Smart Operation of Cranes, 34th International Symposium on Automation and Robotics in Construction (ISARC 2017) (2017).

7. L. Ma; H. Guo; and Y. Fang, Analysis of Construction Workers' Safety Behavior Based on Myers-Briggs Type Indicator Personality Test in a Bridge Construction Project, Journal of Construction Engineering and Management, 147, Issue 1, January 2021.
8. M. A H. Ramalan, M. F. Hasmori, A Study on Human Factor That Leads to Tower Crane Accident at Construction Site in Malaysia, Recent Trends in Civil Engineering and Built Environment 2, 1, 852861, Universiti Tun Hussein, Onn Malaysia Publisher's Office (2021).

9. M. K. Ali; M. I. Mohamad, Crane Failure and Accident in Construction, 141-154 (2016).

10. Neitzel, L. Richard, N. S. Seixas, and K. K. Ren, A Review of Crane Safety in the Construction Industry, 2001, 16, 12, 1106-1117, Nov 2010 (2001).

11. A. Shapira, G. Lucko, \& C. Schexnayder, Cranes for Building Construction Projects, (2007).

12. S. Mohamed, Safety Climate in Construction Site Environments, (2002).

13. J. E. Beavers, P.E. F.ASCE, Moore J. R., R. Rinehart, and W. R. Schriver, Crane-Related Fatalities in the Construction Industry, (2006).

14. A. Sawhney, A. Mund, Adaptive probabilistic neural network-based crane type selection system, J. Constr. Eng. Manag, 128, 265-273 (2002).

15. D. Wu, Y. Lin, X. Wang, S. Gao, Algorithm of crane selection for heavy lifts, J. Comput. Civ. Eng., 25, 57-65 (2021).

16. A. Alshibani, H. Elassir, M. Al-Najjar, H. Hamida, AHP based approach for crane selection of building construction in Saudi Arabia: A case study. In Proceedings of the Annual Conference-Canadian Society for Civil Engineering, Laval, QC, Canada, (2019).

17. H. Safouhi, M. Mouattamid, U. Hermann, A, Hendi, An algorithm for the calculation of feasible mobile crane position areas, Autom. Constr., 20, 360-367 (2011).

18. K. Tantisevi, B. Akinci, Simulation-based identification of possible locations for mobile cranes on construction sites, J. Comput, Civ. Eng., 22,2130, 2008.

19. P.L. Sivakumar, K. Varghese, N.R. Babu, Automated path planning of cooperative crane lifts using heuristic search, J. Comput. Civ. Eng., 17, 197-207 (2003).

20. S. Kang, E. Miranda, Planning and visualization for automated robotic crane erection processes in construction, Autom. Constr, 15, 398-414, (2006).

21. W. Kacalak, Z. Budniak, M. Majewski, Optimization of the movement trajectory of mobile crane working elements. In Advances in Manufacturing; Advances in Manufacturing 475-484, Springer: Cham, Switzerland, (2018).

22. N. Kayhani, H. Taghaddos, A. Mousaei, S. Behzadipour, U. Hermann, Heavy mobile crane lift path planning in congested modular industrial plants using a robotics approach, Autom. Constr., 122, 103508 (2021).

23. S. Tariq, M. Hussein, R. D. Wang, and T. Zayed, Trends and developments of on-site crane layout planning 1983-2020: bibliometric, scientometric, 
and qualitative analyzes, On-site crane layout planning, (2021).

24. G. H. Seong, L. H. Chul, C. B. Yoon, and Y Mi, GABased Optimization Method for Mobile Crane Repositioning Route Planning, Appl. Sci. 11, 6010, 1-18 (2021).

25. Amr S. H. R. Ali, Salah H. R. Ali, Entrepreneurship and Advanced Technologies in Industry, Int. Conference on Advanced Information Tech. and Communication (IC-AITC), Insomnias,(2021).

26. Amr. S.H.R. Ali; E. G. Khalil, Cloud Computing and E-Marketing in Entrepreneurship Development, 1st Int. Conference "Entrepreneurship and SocioEconomic Development" Women Empowerment and Youth Employment, MUST University, Faculty of Management, Economics and Information Systems,1-17, 6th of October City, Giza, Egypt, (2018).

27. E. M. M. M. Shuaib, The Impact of Cloud Computing Applications on Developing Technological Awareness, Journal of Specific Education Research, Faculty of Specific Education, Mansoura University, 126-169, (2017).

28. H. K. Al-Hadrawi, Leadership as an Entrance to Contemporary Business Organizations in the Light of Adopting the Concept of Intellectual Capital (A field study), University of Kufa, Iraq, Al-Ghari Journal of Economic and Administrative Sciences, 27, 9, 85128 (2013).

29. BigRentz, Inc, 11 Types of Cranes Commonly used in Construction, Oct. 2019. On the website at: https://www.bigrentz.com/blog/types-of-cranes

30. D. SDLS, Types of Cranes for Construction \& Industrial Projects, February 2017. On the website at: https://brynthomascranes.com/types-of-cranes/

31. Cranes and Machinery. On the website at: https:/www.gruasyaparejos.com/en/towercrane/types-of-tower-cranes/

32. J. J. Rubio-Ávila, R. Alcántara-Ramírez, J. JaimesPonce, I. I. Siller-Alcalá, Design, construction, and control of a novel tower crane, International Journal of Mathematics and Computers in Simulation, 1, 2, 119 (2007).

33. W. Kacalak, \& Z. Budniak, \& M. Majewski, Computer-aided analysis of the mobile crane handling system using computational intelligence methods. Advances in Intelligent Systems and Computing, 662, 250-261 (2018).

34. A. Trąbka, The influence of clearances in a drive system on dynamics and kinematics of a telescopic crane, Acta Mechanica et Automatica, 9 (1), 9-13 (2015).

35. W. Kacalak, Z. Budniak, M. Majewski, Crane Stability Assessment Method in the Operating Cycle, Transport Problems, 12, Issue 4 (2017).

36. O. N. Anezirisa,\& I. A. Papazoglou, \& M. L. Mud, \& et al. Towards risk assessment for crane activities, Safety Science, 46, 6, 872-884 (2008).

37. EN 17076:2020(MAIN), Tower cranes - Anticollision systems - Safety requirements, (2020).

38. Tower crane equipment, Professional Lift Building Tower Cranes Heavy Equipment Topless with ISO. On the website at: http://www.towercraneequipment.com/chinaprofessional_lift_building_tower_cranes_heavy_equ ipment_topless_with_iso-6134691.html

39. R. Neitzel, N. Seixas, \& K. Ren, Applied Occupational and Environmental Hygiene, A Review of Crane Safety in the Construction Industry, (1047322X), (2010).

40. P. Swuste, A 'normal accident' with a tower crane? An accident analysis was conducted by the Dutch Safety Board, Safety Science, 57, 276-282 (2013).

41. Posted by admin, Crane Accident, New York in (2021)

42. D. A. J. Smith, Crane Operations in Construction: Regulations, Standards, and Liability, Amundsen Smith LLC. On the website at: https://slidetodoc.com/crane-operations-inconstruction-regulations-standards-and-liability/

43. J Collins, How To Manage A Crane Accident,. On the website at: https://becht.com/bechtblog/entry/how-to-manage-a-crane-accident (2019) 